\title{
Synthesis and Electrochemical Properties of CMK-3 with Particles of Nickel, Cobalt and Copper
}

\author{
Yulia N. Zaitseva ${ }^{a}$, \\ Svetlana A. Novikova*a, Vladimir A. Parfenov ${ }^{\text {a }}$, \\ Anton S. Vyatkin ${ }^{\mathrm{b}, \mathrm{c}}$ and Ilya I. Ryzhkov ${ }^{\mathrm{b}, \mathrm{c}}$ \\ a Institute of Chemistry and Chemical Technology SB RAS \\ FRC «Krasnoyarsk Science Center $S B$ RAS» \\ 50/24 Akademgorodok, Krasnoyarsk, 660036, Russia \\ ${ }^{b}$ Institute of computational modeling $S B R A S$ \\ FRC «Krasnoyarsk Science Center SB RAS» \\ 50/44 Akademgorodok, Krasnoyarsk, 660036, Russia \\ ${ }^{c}$ Siberian Federal University \\ 79 Svobodny, Krasnoyarsk, 660041, Russia
} Received 13.06.2019, received in revised form 29.07.2019, accepted 09.08.2019

\begin{abstract}
Mesostructured carbon material CMK-3 for electrodes of electrochemical capacitors was obtained by the method of template synthesis. In order to increase the capacitance characteristics, impregnation of metal ions (Co, $\mathrm{Ni}$, and $\mathrm{Cu}$ ) into the structure of mesoporous carbon CMK-3 was carried out. The structure of the obtained materials was studied by X-ray diffraction and gas adsorption. The study by TEM showed that highly dispersed, nanosized particles are metal oxides $\mathrm{Co}$, Ni and $\mathrm{Cu}$ with the size of 30-50 $\mathrm{nm}$. The particles are uniformly distributed inside the carbon material. Electrochemical characteristics were studied in aqueous electrolytes (1M KCl and $1 \mathrm{M} \mathrm{KOH})$. It has been established that the impregnation of metal ions increases in the specific capacity of the mesoporous carbon material by about $30 \%$ (from 110 to $156 \mathrm{~F} / \mathrm{g}$ ) in $\mathrm{KOH}$.
\end{abstract}

Keywords: electrochemical capacitor, electric double layer, mesostructure, template synthesis, mesoporous mesostructured carbon, $\mathrm{CMK}-3$, metal oxides, $\mathrm{NiO}, \mathrm{CoO}, \mathrm{CuO}, \mathrm{Cu} 2 \mathrm{O}$.

Citation: Zaitseva Yu.N., Novikova S.A., Parfenov A.S., Ryzhkov I.I. Synthesis and electrochemical properties of CMK3 with particles of nickel, cobalt and copper, J. Sib. Fed. Univ. Chem., 2019, 12(3), 295-308. DOI: 10.17516/1998-28360136.

(C) Siberian Federal University. All rights reserved

* Corresponding author E-mail address: snovik.chem@gmail.com 


\title{
Синтез и электрохимические свойства СМК-3 \\ с частицами никеля, кобальта и меди
}

\author{
Ю.Н. Зайцева ${ }^{a}$, С.А. Новикова ${ }^{a}$,

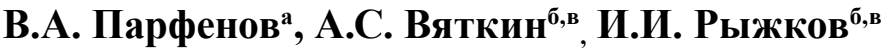 \\ ${ }^{a}$ Институт химии и химической технологии СО РАН \\ ФИЦ «Красноярский научный иентр СО РАН», \\ Россия, 660036, Красноярск, Академгородок, 50/24 \\ ${ }^{6}$ Институт вычислительного моделирования СО РАН \\ ФИЦ «Красноярский научный ичентр СО РАН», \\ Россия, 660036, Красноярск, Академгородок, 50/44 \\ ${ }^{8}$ Сибирский федеральный университет, \\ Россия, 660041 Красноярск, Свободный, 79
}

Методом темплатного синтеза получены мезоструктурированные углеродные материаль СМК-3 для электродов электрохимических конденсаторов. С изелью увеличения емкостньх характеристик проведено импрегнирование ионов металлов (Co, $\mathrm{Ni}$ и Cu) в структуру мезопористого углерода СМК-3. Структура полученных материалов исследована методами рентгеновской дифракции и газовой адсорбции. Исследование методом ПЭМ показало, что высокодисперсные наноразмерные частицы металлов в образияах находятся в виде оксидов $\mathrm{Co}, \mathrm{Ni}$ и $\mathrm{Cu}$, имеют размеры 30-50 нм и равномерно распределены в углеродном материале. Электрохимические характеристики исследованы в водных электролитах (1M KCl и 1 M KOH). Установлено, что внедрение оксидов металлов приводит к увеличению удельной емкости мезопористого углеродного материала примерно на $30 \%$ (om 110 до 156 Ф/2) в среде КОН.

Ключевые слова: электрохимический конденсатор, двойной электрический слой, мезоструктура, темплатный синтез, мезопористый мезоструктурированный углерод, СМК-3, оксиды металлов, $\mathrm{NiO}, \mathrm{CoO}, \mathrm{CuO}, \mathrm{Cu}_{2} \mathrm{O}$.

\section{Введение}

Одно из современных направлений в области разработки перезаряжаемых химических источников электроэнергии - исследования по созданию высокоэффективных электрохимических конденсаторов, использующих процессы перезарядки двойного электрического слоя на поляризуемых электродах с высокой удельной поверхностью. Основным электродным материалом служит высокодисперсный углерод.

Распространенными углеродными наноматериалами являются одно- и многостенные нанотрубки, нановолокна и фуллерены. Использование наноматериалов в электрохимических конденсаторах ограничено их стоимостью, хотя в настоящий момент все больше исследователей отдают им свои предпочтения. Среди таких материалов мезоструктурированный углерод признан лучшим благодаря его упорядоченной пористой структуре, контролируемому диаме- 
тру пор, морфологии и превосходным текстурным параметрам, таким как высокая удельная поверхность и большой объем пор. О популярности упорядоченного мезопористого углерода свидетельствует большое количество работ, посвященных его изучению в качестве материала электрода для конденсаторов [1-11].

В работе [2] была исследована роль размера и структуры пор на электрохимические процессы. В [3-7] определены емкостные характеристики различных мезоструктурированных углеродных материалов в суперконденсаторах на основе двойного электрического слоя. Материал типа СМК-3 привлекает внимание в связи с большой площадью поверхности (около $1000 \mathrm{~cm} 3 / \Gamma$ ), упорядоченной мезопористой структурой, которая способствует доступности поверхности при формировании двойного электрического слоя (ДЭС), скорости внутрипорового ионного переноса и высокой электропроводности [3]. СМК-3 демонстрирует бо́льшую удельную емкость (около 80 Ф/Г), чем CMK-8 - 68 Ф/г [12]. Авторы утверждают, что удельная емкость зависит от площади мезопористой поверхности $\left(\mathrm{S}_{\mathrm{mes}}\right)$, а не от общей удельной площади $\mathrm{BET}\left(\mathrm{S}_{\mathrm{BET}}\right)$.

В работе [13] в качестве источника углерода для приготовления пористых углеродных материалов была использована Кока-кола ${ }^{\circledR}$ с истекшим сроком годности. Удельная емкость приготовленного из безалкогольного напитка углерода составляет 284 Ф/г, что намного выше, чем для материала CMK-3, где источник углерода - сахароза.

Одним из способов улучшения технических характеристик электрода выступает создание композитного материала на основе углерода и металла/оксида металла. В работах [8-9] для увеличения емкости в мезопористый углерод вводили наночастицы оксидов металлов, способные к быстрым фарадеевским реакциям, например оксид кобальта, меди.

В литературе [10] описаны методы введения металлов в СМК-3 пропитыванием нитратами металлов и последующим отжигом при температурах распада нитратов. В [11] показан синтез углеродного материала типа СМК-3 с использованием фурфурилового спирта в качестве источника углерода с предварительным введением нитратов кобальта в исходный SBA-15. В [14] кобальт внедряли добавлением хлорида кобальта на стадии синтеза SBA-15 с последующим восстановлением до металлического кобальта. Введением металлического кобальта удалось повысить удельную емкость материала с 400 до 750 А*ч/г.

Цель данной работы - синтез, изучение физико-химических свойств и установление зависимости электрохимических параметров конденсаторов на основе мезоструктурированного нанопористого углерода СMK-3 с металлами $\mathrm{Co}, \mathrm{Ni}, \mathrm{Cu}$.

\section{Экспериментальная часть}

Для исследования были использованы следующие реактивы: тетраэтоксисилан TEOS (TУ 6-09-3687-74); Pluronic P123 (Sigma Aldrich, CAS: 9003-11-6); HCl, ч.д.а.; $\mathrm{H}_{2} \mathrm{SO}_{4}$, х.ч.; $\mathrm{NH}_{4} \mathrm{~F}$, ч.д.а.; $\mathrm{NaOH}$, х.ч.; $\mathrm{Co}\left(\mathrm{NO}_{3}\right)_{2} \cdot 6 \mathrm{H}_{2} \mathrm{O}$, х.ч.; $\mathrm{Ni}\left(\mathrm{NO}_{3}\right)_{2} \cdot 6 \mathrm{H}_{2} \mathrm{O}$, х.ч.; $\mathrm{Cu}\left(\mathrm{NO}_{3}\right)_{2} \cdot 6 \mathrm{H}_{2} \mathrm{O}$, х.ч.

\section{Синтез СМК-3 с наночастицами кобальта и никеля}

В качестве прекурсора CMK-3 применен силикатный материал SBA-15, синтезированный канд. хим. наук И.В. Пономаренко согласно методике, описанной в [15]. В процессе синтеза SBA-15 на стадии первичного осаждения TEOS был введен фторид аммония в количестве $0,25 \mathrm{~F} / \mathrm{Si}$.

$$
-397-
$$


Внедрение ионов металлов в углеродный материал проводили непосредственно в процессе синтеза СМК-3 добавлением солей металлов в силикатный материал SBA-15. Расчет количества металлов в готовом образце СМК-3 делали исходя из того, что в готовых образцах СМК-3 образуются оксиды металлов в количестве $~ 10 \%$. Порошок SBA-15 пропитывали водными растворами нитратов кобальта 0,0804 г / никеля 0,1940 г / меди 0,1850 г в расчете на 1 г SBA-15. Импрегнированный ионами металлов SBA-15 сушили на воздухе. Затем полученный материал двукратно пропитывали раствором сахарозы согласно методике, описанной в работах $[16,17]$. Для первой стадии пропитки на 1 г материала готовили раствор, состоящий из 5 мл воды, 1,25 г сахарозы и 0,14 г серной кислоты. После этого материал сушили при $100{ }^{\circ} \mathrm{C}$ в течение 6 часов. Затем проводили вторую стадию пропитки раствором, состоящим из 5 мл воды, 0,8 г сахарозы и 0,09 г серной кислоты. Материал повторно высушивали при $100{ }^{\circ} \mathrm{C}$ в течение 6 часов. Далее на этапе карамелизации сахарозы температуру увеличивали до $160{ }^{\circ} \mathrm{C}$ и выдерживали образцы еще в течение 6 часов. Высокотемпературную карбонизацию образцов проводили в токе азота при температуре 850-900 ${ }^{\circ} \mathrm{C}$ (подъем температуры осуществляли в течение 2,5 часов, выдержка 2,5 часа). Удаление силикатного темплата проводили в два этапа: 1) выдержка образцов в 1 М растворе $\mathrm{NaOH}$ при температуpe $100{ }^{\circ} \mathrm{C}$ в течение 16 часов; 2) выдержка в $0,1 \mathrm{M}$ растворе $\mathrm{NaOH}$ при $80^{\circ} \mathrm{C}$ в течение 6 часов. После растворения силикатной составляющей образцы извлекали из раствора, тщательно промывали дистиллированной водой и сушили на воздухе при температуре $120^{\circ} \mathrm{C}$. Готовые образцы чистого углеродного материала СМК-3 и с ионами металлов были получены в виде формованных таблеток диаметром 13 мм, толщиной 3-4 мм. Масса полученных образцов составляла около 0,4 г.

Обозначение образцов: СМК-3 - углеродный материала без металла, $\mathrm{Me} / \mathrm{CMK}-3$ (Me = Co, $\mathrm{Ni}, \mathrm{Cu})$ - углеродный материал с добавками кобальта, никеля и меди соответственно.

\section{Физико-химические методы исследования}

Регистрацию рентгенограмм производили на дифрактометре X'Pert Pro (PANalytical, Нидерланды) с полупроводниковым детектором PIXcel и графитовым монохроматором на вторичном луче с фокусировкой по Бреггу-Брентано, $\mathrm{Cu}_{\mathrm{K} \alpha 1,2}$ излучение. Текстурные характеристики образцов изучали на анализаторе удельной поверхности ASAP 2420 (Micromeritics, США). Полученные изотермы адсорбции анализировали для расчета удельной поверхности образца $\left(\mathrm{S}_{\mathrm{BET}}\right)$ методом ВЕТ [18], площади микро- и мезопор $\left(\mathrm{S}_{\text {micro }}\right.$ и $\left.\mathrm{S}_{\mathrm{meso}}\right)$ и общего объема пор методом ВJН ( $\mathrm{V}_{\text {ВJн}}$ ) [19]. Полуколичественный элементный анализ полученных композитных материалов проводили на рентгенофлуоресцентном спектрометре Axios Advanced (PANalytical, Нидерланды). Анализ морфологической структуры образцов делали методом просвечивающей электронной микроскопии на электронном микроскопе Hitachi HT7700.

Электрохимические исследования выполняли в стандартной трехэлектродной ячейке при $25{ }^{\circ} \mathrm{C}$ в $1 \mathrm{M}$ растворах хлорида калия и гидроксида калия. В качестве вспомогательного электрода использовали платиновую проволоку, для сравнения - хлорсеребряный электрод с концентрацией $\mathrm{KCl}$ 4,2 М. Циклические вольтамперные (ЦВА) кривые получены на потенциостате Elins P20-X (Electrochemical Instruments, Россия). Удельную емкость рассчитывали по формуле: 


$$
C_{\text {specific }}=\frac{1}{m v\left(U_{1}-U_{0}\right)} \int_{U_{0}}^{U_{1}} I(U) d U,
$$

где $m$ - масса образца, $v$ - скорость развертки, $U_{0}$ и $U_{1}$ - пределы интегрирования ЦВА кривой.

\section{Результаты и обсуждение}

На рис. 1 приведены рентгенограммы образцов в малоугловой и дальней областях. Рентгенограммы в малоугловой области показывают, что мезоструктура углеродного материала сохранилась после внедрения частиц металлов. Дальняя угловая область указывает на то, в каком виде содержатся частицы в углеродном образце CMK-3. На дифрактограммах дальней области всех образцов (рис. 1) можно видеть одну широкую полосу в области 10-30, свидетельствующую об аморфной структуре углерода. Установлено, что кобальт в значительной степени вымылся из образца и содержится в виде $\mathrm{CoO}$, никель присутствует в виде $\mathrm{NiO}$, медь в виде $\mathrm{CuO}, \mathrm{Cu}_{2} \mathrm{O}$. По данным рентгенофлуоресцентного анализа, содержание кобальта в образце 0,46 масс. \%, содержание никеля 4,97 масс. \%, меди - 12,6 масс. \% в пересчете на чистый металл.

На рис. 2 показаны изотермы адсорбции азота и распределение пор по размерам для образцов CMK-3 и Me/CMK-3. Все образцы демонстрируют изотермы адсорбции IV типа с четко выраженной стадией капиллярной конденсации, что характерно для упорядоченных мезопористых материалов с однородным распределением пор по размерам.

В табл. 1 приведены суммарные структурные и текстурные характеристики СМК-3 и его композитов с металлами. Удельная поверхность СМК-3 значительно (в 2 раза) выше, чем у его композитов, однако это связано с высокой долей микропористой поверхности, составляющей половину от общего значения. Композиты с металлами имеют меньшую удельную поверхность и объем пор, чем СМК-3. Удельная поверхность образца Со/СMК-3 немного выше (903 м²/г)

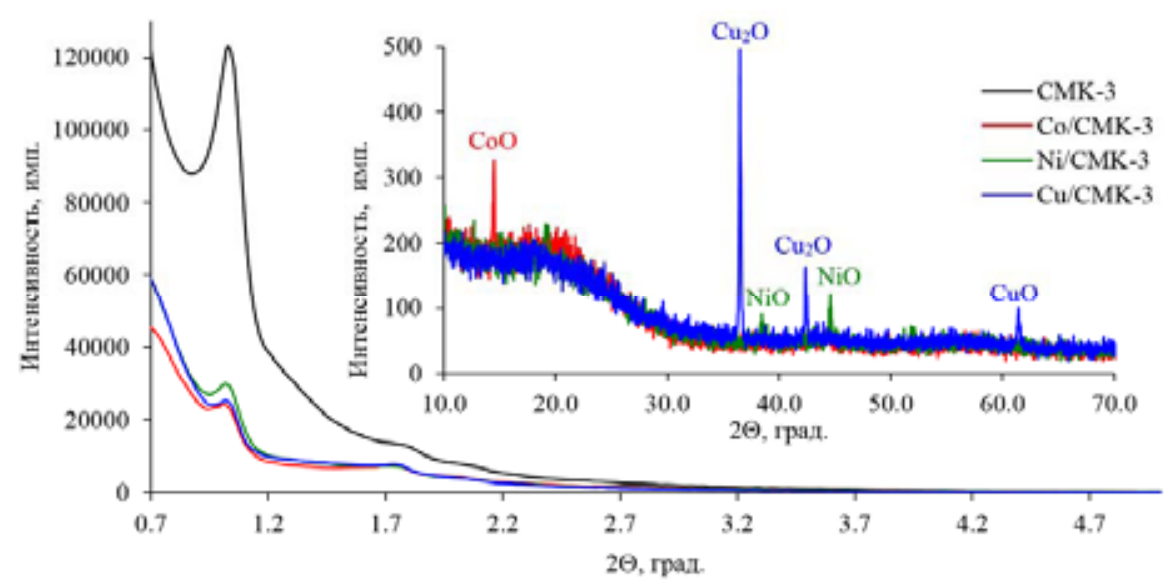

Рис. 1. Малоугловая область рентгенограммы образцов: CMK-3, Co/CMK-3, Ni/CMK-3 и Cu/CMK-3. На вставке представлена дальняя область

Fig. 1. Small-angle X-ray patterns of samples: CMK-3, Co/CMK-3, Ni/CMK-3 and Cu/CMK-3. The inset shows the X-ray patterns 

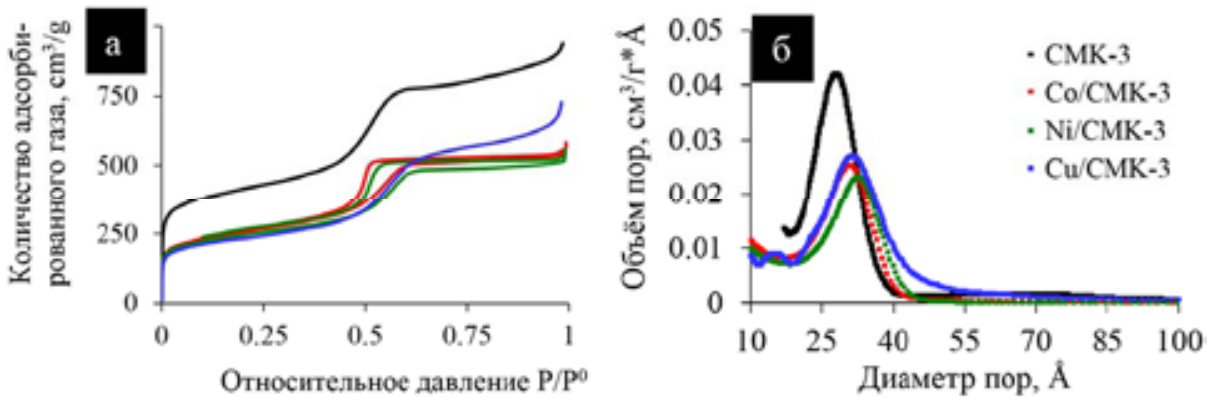

Рис. 2. Изотермы адсорбции (а) и распределение пор по размерам (б) для адсорбционной области изотермы образцов СМК-3 и Ме/CMK-3

Fig. 2. Adsorption isotherms (a) and pore size distribution (b) for the adsorption region of the isotherm of CMK-3 and Me/CMK-3 samples

Таблица 1. Структурные и текстурные характеристики СМК-3 и его композитов с металлами

Table 1. The structural and textural characteristics of CMK-3 and its composites with metals

\begin{tabular}{|c|c|c|c|c|c|c|c|c|c|}
\hline Образец & $\begin{array}{c}\text { Положение } \\
1 \text {-го пика } \\
2 \Theta_{(100)}, \text { град. }\end{array}$ & $\begin{array}{c}\text { Параметр } \\
\text { ячейки } \mathrm{a}_{100} \text {, } \\
\text { нм }\end{array}$ & $\begin{array}{c}\text { Толщина } \\
\text { стенки, нм }\end{array}$ & $\begin{array}{l}\mathrm{S}_{\mathrm{BET}}, \\
\mathrm{M}^{2} / \Gamma\end{array}$ & $\begin{array}{l}\mathrm{V}_{\text {BJH }}, \\
\mathrm{cm}^{3} / \Gamma\end{array}$ & $\begin{array}{l}\mathrm{S}_{\text {micro, }} \\
\mathrm{M}^{2} / \Gamma\end{array}$ & $\begin{array}{l}\mathrm{V}_{\text {micro, }}, \\
\mathrm{cm}^{3} / \Gamma\end{array}$ & $\begin{array}{l}\mathrm{S}_{\text {meso }} \\
\mathrm{M}^{2} / \Gamma\end{array}$ & $\begin{array}{c}\mathrm{D}_{\text {пор }}, \\
\mathrm{HM}\end{array}$ \\
\hline CMK-3 & 1,03 & 9,9 & 4,3 & 1519 & 2,14 & 754 & 0,31 & 765 & 5,6 \\
\hline \begin{tabular}{|c|}
$\mathrm{Co} / \mathrm{CMK}-3$ \\
\end{tabular} & 1,01 & 10,1 & 6,3 & 903 & 0,85 & 342 & 0,15 & 561 & 3,8 \\
\hline \begin{tabular}{|l|}
$\mathrm{Ni} / \mathrm{CMK}-3$ \\
\end{tabular} & 1,02 & 10,0 & 6,0 & 857 & 0,85 & 366 & 0,17 & 491 & 4,0 \\
\hline \begin{tabular}{|c|}
$\mathrm{Cu} / \mathrm{CMK}-3$ \\
\end{tabular} & 1,01 & 10,1 & 4,2 & 835 & 1,24 & 368 & 0,16 & 467 & 5,9 \\
\hline
\end{tabular}

остальных композитов в связи с тем, что, как было указано выше, кобальт в значительной степени вымылся из образца.

На рис. 3 приведены микрофотографии образцов, полученные просвечивающей электронной микроскопией. На рис. $3 a$ дана микрофотография материала СМК-3. На рис. 36 приведен снимок композитного материала Ni/CMK-3. У композитного образца с никелем сохраняется сотообразная канальная структура. Мелкие темные частицы на фотографии представляют собой вторую фазу. Микроанализ показывает, что они состоят в основном из оксида никеля и равномерно распределены по всему материалу. Размер включений составляет 30-50 нм. Образец после всех процедур (пропитывание, прокаливание и отмывка) сохраняет структуру, характерную для материалов типа СМК-3.

Образцы Co/CMK-3, Ni/CMK-3 и Cu/CMК-3 имеют сопротивление от 10 до 30 Ом. ЦВА кривые, снятые в диапазоне от -600 до 600 мВ в водном растворе электролита $\mathrm{KCl}$ с различной скоростью развертки потенциала (1-20 мВ/с) для исследуемых углеродных материалов, представлены на рис. 4a-б. Снижение удельной емкости при увеличении скорости развертки потенциала (рис. 42) связано с уменьшением доступности внутренней поверхности пор, поскольку процесс формирования ДЭС протекает преимущественно на внешней их поверхности и определяется как размером иона электролита, так и структурой электрода. При низких скоростях развертки потенциала ионы электролита имеют достаточно времени для диффузии в 

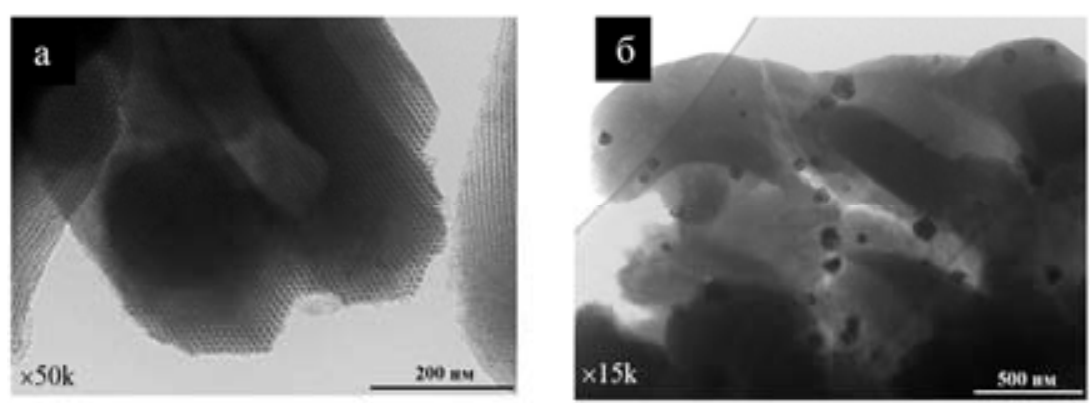

Рис. 3. Изображения, полученные просвечивающей электронной микроскопией: а - образец СМК-3, б образец $\mathrm{Ni} / \mathrm{CMK}-3$

Fig. 3. TEM images of samples: a) CMK-3, b) Ni/CMK-3
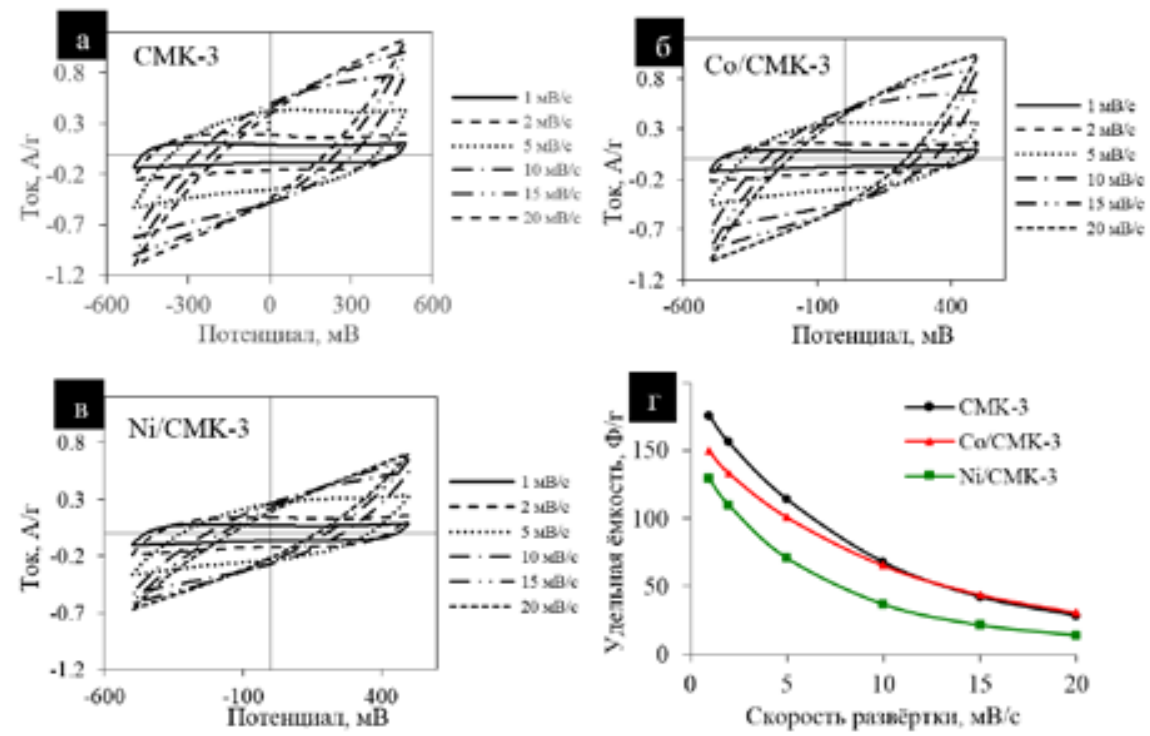

Рис. 4. ЦВА кривые (а-в) и зависимость удельной емкости от скорости развертки (г) для исследуемых образцов в электролите $1 \mathrm{M} \mathrm{KCl}$

Fig. 4. Voltammograms (а-в) and the specific capacity (г) of the samples studied in $1 \mathrm{M} \mathrm{KCl}$ electrolyte at the different scan rates

микропоры углеродного материала, а при высоких - данный тип пор не участвует в процессе заряжения ДЭС.

На рис. 5 приведены ЦВА кривые образцов, снятые в диапазоне от -500 до 100 мВ в 1 М растворе КОН. Вольтамперограммы преимущественно имеют прямоугольную форму, характерную для обратимых процессов заряда и разряда двойного электрического слоя. Однако форма кривых ЦВА немного меняется в зависимости от типа металла в образцах. Для $\mathrm{Cu} / \mathrm{CMK}-3$ наблюдается пик в потенциальном окне от -200 до -100 мВ, который, вероятно, обусловлен реакцией

$$
\mathrm{Cu}_{2} \mathrm{O}+\mathrm{H}_{2} \mathrm{O}+2 \mathrm{e}^{-} \rightarrow 2 \mathrm{Cu}+2 \mathrm{OH}^{-}
$$



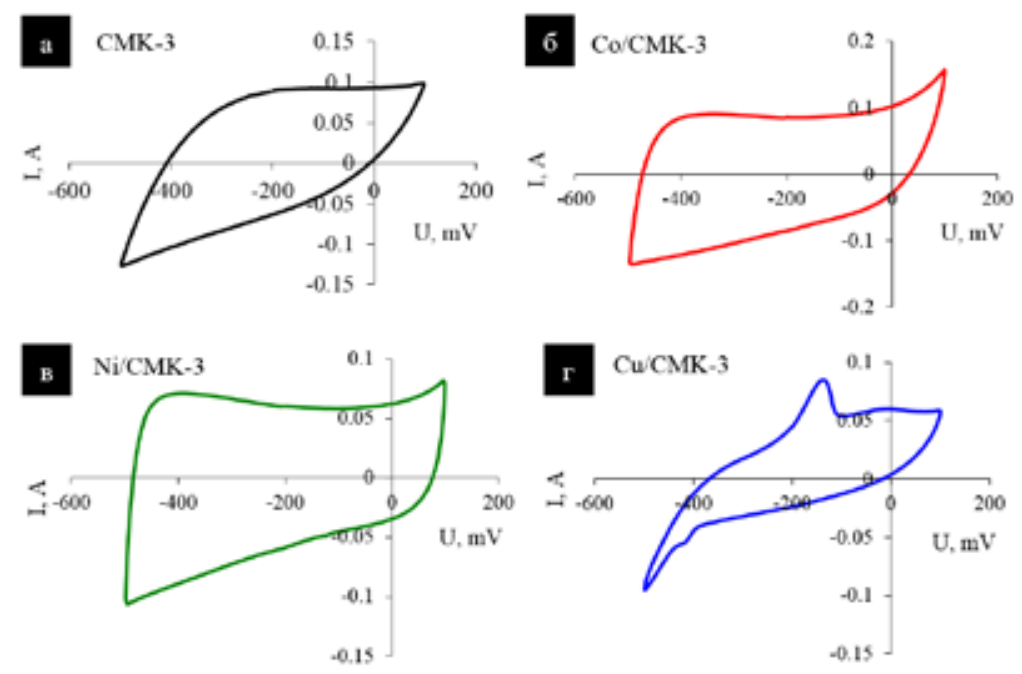

Рис. 5. ЦВА кривые в 1 М растворе КОН при скорости развертки потенциала $1 \mathrm{MB} / \mathrm{c}$

Fig. 5. Voltammograms of the samples in $1 \mathrm{M} \mathrm{KOH}$ electrolyte at a potential scan rate of $1 \mathrm{mV} / \mathrm{s}$ )

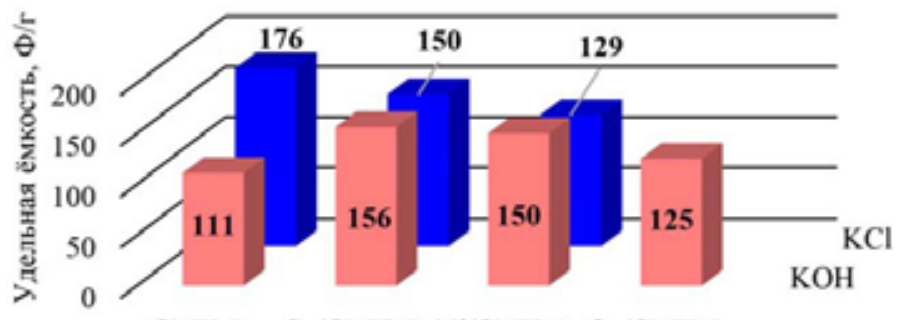

CMK-3 $\mathrm{Co} / \mathrm{CMK}-3 \quad \mathrm{Ni} / \mathrm{CMK}-3 \quad \mathrm{Cu} / \mathrm{CMK}-3$

Рис. 6. Удельная емкость образцов в $1 \mathrm{M}$ растворах $\mathrm{KCl}$ и $\mathrm{KOH}$

Fig. 6. Specific capacity of the samples in $1 \mathrm{M} \mathrm{KCl}$ and $\mathrm{KOH}$ electrolytes

со стандартным электродным потенциалом -360 мВ относительно стандартного водородного электрода (что соответствует -138 мВ относительно 4,2 M Ag/AgCl электрода) [20]. Присутствие в образе оксида меди $\mathrm{Cu}_{2} \mathrm{O}$ подтверждается результатами рентгенофазового анализа (рис. 1).

Сравнение удельных емкостей представлено на рис. 6. Наличие оксидов металлов в структуре мезоструктурированного углерода приводит к уменьшению удельной емкости при измерении вольтамперных кривых в $1 \mathrm{M}$ растворе $\mathrm{KCl}$ и к увеличению удельной емкости - в $1 \mathrm{M}$ растворе $\mathrm{KOH}$.

\section{Заключение}

Методом темплатного синтеза получены мезоструктурированные углеродные материалы СМК-3 для электродов электрохимических конденсаторов с включением ионов металлов $(\mathrm{Co}, \mathrm{Ni}$ и $\mathrm{Cu})$. Структура полученных материалов исследована методами рентгеновской дифракции и газовой адсорбции. Установлено, что мезоструктура в результате внедрения метал- 
лов полностью сохраняется. Металлы присутствуют в виде оксидов ( $\left.\mathrm{CoO}, \mathrm{CuO}, \mathrm{Cu}_{2} \mathrm{O}, \mathrm{NiO}\right)$. Электрохимические характеристики исследованы в водных электролитах $1 \mathrm{M} \mathrm{KCl}$ и $1 \mathrm{M} \mathrm{KOH}$. Импрегнирование оксидов металлов приводит к увеличению удельной емкости мезопористого углеродного материала примерно на 30 \% (от 110 до 156 Ф/г) в среде 1 М КОН. Таким образом, показана перспективность использования мезоструктурированного углерода, полученного темплатным способом, для электродов электрохимических конденсаторов.

\section{Благодарности}

Авторы выражают благодарность кандидату химических ннаук И.В. Пономаренко за предоставленный исходный силикатный материал SBA-15.

\section{Список литературы}

1. Lokhande V.C., Lokhande A.C., Lokhande C.D. et al. Supercapacitive composite metal oxide electrodes formed with carbon, metal oxides and conducting polymers. J. Alloy Compd. 2016. Vol. 682, P. 381-403.

2. Phan T.N., Gong, M.K., Thangavel R., et al. Enhanced electrochemical performance for EDLC using ordered mesoporous carbons (CMK-3 and CMK-8): Role of mesopores and mesopore structures. J. Alloy Compd. 2019. Vol. 780, P. 90-97.

3. Соляникова А.С., Чайка М.Ю., Боряк А.В. и др. Композитные электроды электрохимических конденсаторов на основе углеродных материалов различной структуры. Электрохимия 2014. T. 50, C. 470. [Solyanikova A.S., Chayka M.Yu., Boryak A.V., et al. Russ. J. Electrochem. 2014. Vol. 50. P. 419 (In Russ.)]

4. Li H., Xi H., Zhu S., et. al. Preparation, structural characterization, and electrochemical properties of chemically modified mesoporous carbon. Micropor. Mesopor. Mater. 2006. Vol. 96, P. 357-362.

5. Xing W., Qiao S. Z., Ding R.G., et.al. Superior electric double layer capacitors using ordered mesoporous carbons. Carbon. 2006. Vol. 44, P. 216-224.

6. Lei Z., Bai D., Zhao X.S. Improving the electrocapacitive properties of mesoporous CMK-5 carbon with carbon nanotubes and nitrogen doping. Micropor. Mesopor. Mater. 2012. Vol. 147, P. $86-93$.

7. Пономаренко И.В., Соляникова А.С., Чайка М.Ю. и др. Активация мезоструктурированных электродных материалов электрохимических конденсаторов. Электрохимия 2015. Т.51. C. 863-872 [Ponomarenko I.V., Solyanikova A. S., Chayka M. Yu., et al. Russ. J. Electrochem. 2015. Vol. 51, P. 764 -772 (In Russ.)]

8. Huwe H., Fröba M. Synthesis and characterization of transition metal and metal oxide nanoparticles inside mesoporous carbon CMK-3. Carbon. 2007. Vol. 45, P. 304-314.

9. Prasad K.R.S., Dhawale D.S., Joseph S. et.al. Post-synthetic functionalization of mesoporous carbon electrodes with copper oxide nanoparticles for supercapacitor application. Micropor. Mesopor. Mater. 2013. Vol. 45, P. 304.

10. Zhao C., Li J., Chen W., et al. Synthesis and electrochemical properties of ordered mesoporous carbon supported well-dispersed cobalt oxide nanoparticles for supercapacitor. Mater. Res. Bull. 2015. Vol. 64, P. 55-60. 
11. Park I.-S., Choi M., Kim T.-W., et al. Synthesis of magnetically separable ordered mesoporous carbons using furfuryl alcohol and cobalt nitrate in a silica template. J. Mater. Chem. 2006. Vol. 16, P. 3409-3416.

12. Phan T.N., Gong M.K., Thangavel R., et al. Enhanced electrochemical performance for EDLC using ordered mesoporous carbons (CMK-3 and CMK-8): Role of mesopores and mesopores structures. J. Alloy Compd. 2019. Vol. 780, P. 90-97.

13. Stalin J., Devaraju M.K., Mercy R.B., et. al. Highly ordered mesoporous carbons with high specific surface area from carbonated soft drink for supercapacitor application. Micropor. Mesopor. Mater. 2019. Vol. 280, P. 337-346.

14. Qiao H., Yu Y., Xia Z., et al. Hydrothermal synthesis and high electrochemical performance of ordered mesoporous Co/CMK-3 nanocomposites. Ionics. 2017. Vol. 24(3), P. 715-721.

15. Parfenov V.A., Ponomarenko I.V., Novikova S.A. Structural consequences of the fluorides using in the synthesis of SBA-15 mesostructured silica. Mat. Chem. Phys. 2019. Vol. 232, P. 193-199.

16. Shinae J., Joo S.H., Ryoo R., et. al. Synthesis of New, Nanoporous Carbon with Hexagonally Ordered Mesostructure. J. Am. Chem. Soc. 2000. Vol. 122, P. 10712-10713.

17. Ryoo R., Joo S.H., Kruk M., et al. Ordered mesoporous carbons. Adv. Mater. 2001. Vol. 13(9). P. 677-681.

18. Gregg S.J., and Sing K.S.W. Adsorbtion, Surface Area and Porosity. Academic Press, New York, 1982.

19. Kruk M., Jaroniec M., Sayari A. Application of Large Pore MCM-41 Molecular Sieves To Improve Pore Size Analysis Using Nitrogen Adsorption Measurements. Langmuir. 1997. Vol. 13(23), P. 6267-6273.

20. Лурье Ю.Ю. Справочник по аналитической химии. М.: Химия, 1989. 448 с. [Lurie Yu.Yu. Handbook of Analytical Chemistry. Moscow, Chemistry, 1989. 448 p. (In Russ.)] 